\title{
Strategies to Maximise Staff Retention Among Millennial Teachers in Bangkok International Schools
}

\author{
Karl Meneghella ${ }^{1}$, John Walsh ${ }^{2}$, \& Ousanee Sawagvudcharee ${ }^{1}$ \\ ${ }^{1}$ School of Management, Shinawatra International University, Bangkok, Thailand \\ ${ }^{2}$ School of Business and Management, RMIT, Vietnam \\ Correspondence: Karl Meneghella, School of Management, Shinawatra International University, Bangkok \\ Thailand. Tel: 66-86-363-2826. E-mail: karl@edu.kis.ac.th
}

Received: June 20, 2019 Accepted: June 30, $2019 \quad$ Online Published: July 23, 2019

doi:10.5539/ass.v15n8p70 URL: https://doi.org/10.5539/ass.v15n8p70

\begin{abstract}
Changes to the education landscape in recent times include increased globalisation, evolving national curricula, the need for a more global education, attracting and retaining value-adding faculty members and the increased competition to attract students. Schools also need to deal with a shrinking pool of available teachers as enrolment by young people into teacher education degrees are falling and many mature teachers are retiring from teaching. These changes in the teaching landscape are all having an impact on the ways schools conduct business, and it is particularly true in the international school setting. A significant proportion of teachers in international schools are less than 40 years old (aka millennials). Millennials have been the focus of some research of late, and initial findings would indicate that there are a lot of unknowns and misconceptions surrounding their expectations, their world view, and how to best utilise them in the workforce. Following these lines of inquiry, it is believed that identifying some of these potential generational differences in needs and wants will assist schools in developing sustainable strategies for the attraction, development and retention of young teachers, in turn creating increased efficiency and competitive advantage for the school.
\end{abstract}

Keywords: attraction, retention, millennials, international schools

\section{Introduction}

The post-war decades of the 1950s and 60s saw a dramatic increase in globalisation and with this, a dramatic increase in international trade. This changing environment was the petri-dish for a new evolution in business, to wit, the international businessman. These expatriates were often relocated to take on senior management roles for multi-national concerns, or to oversee the operation of specialised equipment and processes (Bunnell, 2014). Along with other expatriates, such as the diplomatic community and Non-Government Organisations staff (NGOs), these internationally mobile people wanted (where practical and possible) to keep their families intact, and to do this, they needed schools for their children to attend (Hayden \& Thompson, 2008). Added to this, they wanted schools which offered the same, or at least a similar curriculum, to those on offer in their home countries. It was thought that this similarity in schooling would mitigate some of the barriers to their children's successful transition back to a local school setting once their parents' diplomatic posting or business obligations were concluded. This was arguably the birth of the modern day international school. Initially, the growth of this sector was quite slow for the first 40 years or so. However, in the past decade, it has seen exponential growth as more and more countries have increasing middle-class sectors that can afford to send their children to an international school.

The demand for an English-medium international school education has been growing steadily over the last 20 years. The international school sector has brought in an estimated US\$34.4 billion in 2013, (up from \$20 billion in 2009), while educating close to 3.5 million students in 238 countries across the world. International schools are "no longer a small market catering to a niche group," rather "the international schools market is now big business and is recognized as such by a broad range of investors, suppliers and providers (Clark, 2014).

The market is driven predominantly by the richest $5 \%$ of non-English-speaking families who want places for their children at international schools in their home countries (Keeling, 2015). This local demand is expected to 
increase as economies continue to prosper and incomes rise. There is wide-scale acceptance that a student who attends an international school, with its English-speaking education and typically high-standards of teaching and learning, has access to a much broader choice of higher education, including the best universities in the world. As a result, international school attendance is placed high on the priority list of many families, providing they can afford it. The International School Consultancy (ISC) estimates that local children now fill $80 \%$ of international school places (Keeling, 2015).

Whilst affordability is a hurdle to overcome (even for the local upper middle class), there are other drivers prompting parents to seek international school placements for their children. In 'The Report Thailand 2012', reference was made to Thailand's education system and the following observations were made.

Despite recent steps towards improvement, the public school system has a record of poor accountability, politicisation, corruption and opaque enrolment processes - all factors that contribute to undermined public confidence. The system is typically presented as relying on outdated rote learning methods and curricula that does not encourage critical thinking nor [does it] provide [the] necessary skills to compete in the labour market or broader economy. Almost 30,000 schools need support to bring them up to national standards, according to the Thailand Ministry of Education and examination results have done little to dispel concerns (Andrews, 2012).

Whilst international schools can be said (in light of the local salaries paid to mid-level executives) to be very expensive in a local market context, it does not deter those Thai nationals who can afford the tuition fees from enrolling their children. This is in part due to the perception that Thai schools are inferior to international schools as highlighted in 'The Report Thailand 2012' as well as the desire to have their children participating in an internationally accredited curriculum where English is the medium of instruction.

Some of the fastest growing economies are located in South East and East Asia. This growth has resulted in increased opportunities for local entrepreneurs and increased numbers of middle to high-income families. This economic ability to pay higher tuition fees has created another potential customer for the international school. This customer is not an expatriate per se but often a local entrepreneur who desires a western education for his or her children where English is the Medium of Instruction (EMI). These English Medium Schools (EMS) are attracting increasing numbers of local indigenous students and the schools often enjoy extensive waiting lists of local students.

If the literature is to be believed, the international school market is poised to dramatically expand over the next decade, almost doubling from where it is today. Bearing in mind that this growth has historically been a gradual one over the past $100+$ years, a doubling effect in 10 years is something that has no precedence and in turn, will challenge the market and its capabilities.

The physical location of a school is a significant consideration; schools need to be in proximity to where the target families live. If they are targeting and/or catering for high-earning families, chances are that these families are living in high-cost areas. Additionally, these high-earning individuals have expectations for convenience and access and do not want to have to commute for hours on end. This creates a financial burden on new schools opening in sought after locales in order to address this market. The buildings, resources, facilities and environment need to be world-class. The families will have increasing choices and the grounds, buildings and offerings for children are part of the competitive landscape. The school needs to be able to deliver an internationally accredited curriculum through teachers who are internationally trained, holding relevant degrees and are demonstrably passionate about pedagogy and learning. For the purposes of this paper, they are described as top-tier teachers.

It is this latter point, the one of top-tier teachers that presents the biggest hurdle schools will need to overcome if they are to successfully position themselves in this growing market. Who will be delivering the curriculum? There is already a shortage of generalist teachers in many English speaking countries and if we are to look at exemplary high-quality or top-tier teachers, then perhaps the shortage is even more acute. International schools will need to deal with the attraction, development and retention of suitably qualified teachers, further, they will have to do so in an environment of greater competition, greater mobility and a new workforce that do not necessarily follow the predicable behaviours of previous teacher cohorts.

We may ask ourselves: What are the Characteristics of an International School? Ian Hill, in his article, "What is an International School" takes the reader on an historical journey looking at the typology of international schools and the efforts of researchers to try and categorise them in a meaningful and useful way. This may sound trivial or redundant, however in the context of Thailand, many schools offer themselves as 'international' without having either international teachers, an accredited international curriculum, or for that matter, a preponderance of 
international students. Without surveying all of the international schools in Asia it is impossible to say with any degree of certainty if this is the case in other countries but it is a reasonable assumption to make and it is this reality that prompted the classification of international schools for research purposes.

The following four categories provide a qualitative lens with which to view international schools. The first of these four are elite private national schools within the home country. They mostly cater for students from the home country in which they are located. They promote an international perspective and student exchanges abroad. The second category are overseas schools offering home education to expatriates abroad in schools usually funded in large measure by the home country's government. Their students are normally of the home-country nationality, for example USA, British, French, German and Swiss overseas schools tend to have a predominance of US, UK, French, German and Swiss students respectively. Also included in this category are missionary schools. Ian Hill's third category are those few institutions emanating from bilateral or multilateral agreements between governments such as a few French-German schools and the European (Common Market) schools (offering the European Baccalaureate from 1959). Fourth and finally are those genuine international school's that are, or could be ISA members (Leach, 1969).

So, for the purpose of this paper, we will be looking at international school as institutions that have the following attributes.

- A significant percentage of international student enrolments. (We define international students as those students who are not nationals of the host-country or have at least one parent who is not a national of the host-country.)

- A Board of Directors comprised of both national and foreign members.

- An expatriate homeroom teaching staff. (The emphasis here is that the key teaching roles are carried out by English Speaking Country (ESC) nationals and thus have themselves experienced cultural adaptation, and are therefore equipped to counsel students and mentor them in their cultural adaption experiences). Additionally, the students are being exposed to a variety of accents and colloquial English. And finally,

- A curriculum equivalent to, or better than that, enjoyed back in the foreign student's home country.

Additionally, it is recognised that international schools may have 1 of 3 prominent foci. They may be 'traditional', market-driven schools for the children of expatriates and predominately whether for-profit or not-for-profit. Or alternatively, the school may be an 'ideological', mission-driven enterprise to promote international understanding and peace such as the United World Colleges or Salman Khan's, Kahn Academy. Or finally, the school may be a 'non-traditional', market-driven school predominately for the local elite, and also predominately for-profit (Hayden \& Thompson, 2013).

There are two distinct variations to the core raison d'etre of international schools, these are being market driven or being ideologically driven (Matthews, 1989). Market-driven schools arose from the needs of a particular expatriate community and a desire to respond to and fill that need or vacuum. The schools that were led by ideology were, by and large, founded for the express purpose of either furthering a religious imperative, furthering international mindedness and/or furthering understanding and cooperation between people (Husen \& Postlethwaite, 1985).

So in summary, we have a school offering an international curriculum to an international student body by internationally trained teachers. The student body is comprised of both local families and expatriate families. One of the problems with a lot of research dealing with expatriates is that it tends to focus on the citizens of first world countries being relocated to third-world or developing countries. This is indeed true of some if not the majority of expatriate families enrolling at an international school but is not exclusively so. In a survey of 38 Grade 2 student's families in a Bangkok international school the following data was uncovered.

Table 1. Family Demographics

\begin{tabular}{cccc}
\hline Parents of families & Both Thai & 1 Thai 1 Foreign & Both foreign \\
\hline Local & 16 & 9 & 1 \\
Expatriate & & 2 & 7 \\
SIE & 16 & 2 & 1 \\
Totals & 13 & 13 & 9 \\
\hline
\end{tabular}

As can be seen with the results, not only are there different types of expatriation but marked differences in the family compositions. The bulk of the literature on expatriates oftentimes clouds the issue due to its focus on the 
western executive travelling to remote outposts of the multi-national company. Filipina maids working in the USA are expatriates, admittedly, they may be self-initiated expatriates but they are expatriates as are Burmese domestic workers in Thailand and Indian construction workers in Singapore.

For the purposes of this paper, the term expatriate is used to describe people who are legally working or residing in a country foreign to their citizenship status. Further to this, the word expatriate also includes the notion of career; in other words, these foreign people that are 'working' in their host country (Reiche \& Harzig, 2009). Additionally, these people may have been relocated by their parent organisation (Deployed Expatriates DEs) or may be, as is the case with a lot of teachers in international schools, Self-Initiated Expatriates (SIEs). Finally, we also include the group of people who reside in a foreign country and get employed on a (typically) local contract. These Locally Employed Expatiates (LEE) are not as rare as one may at first imagine (McNulty, 2017). The emigration rate for skilled migrants (of which teachers qualify) has been steadily increasing and according to OECD the total number of international migrants worldwide exceeds 110 million. (Population aged 15 or over), and highly skilled migrants represents over 23 million workers or $21.5 \%$ of the whole (Black, Mendenhall, \& Oddou, 1991). This exodus of talent from a country is typically referred to as "brain drain" (Baruch, Budhwar, \& Khatri, 2007; Forstenlechner, 2010; Pearson, Hammond, Heffernan, \& Turner, 2012), while the inverse is that some countries are receiving a "brain gain" (Tung \& Lazarova, 2006). In the case of Multi-National Companies (MNCs) they have a potentially larger pool of applicant from which to select (Felker, 2011; Pearson et al., 2012). The implications are clear. The more that is known about the relocation drivers and the SIE's expectations and needs, the better equipped HR departments will be in managing and developing the key personnel.

The underlying reasons to better define and understand expatriates and the migration of expatriates is that we are dealing with 3 distinct types of expatriates in this paper. The student body of international schools is primarily made up of local children and the children of deployed expatriates. However, we are seeing an increasing number of children from Locally Employed Expatriate families being represented in the student body. Finally, the paper will be looking at the attraction and retention of teachers and these are, for the most part, either Self-Initiated Expatriates or Locally Employed Expatriates (also known as Local Hires).

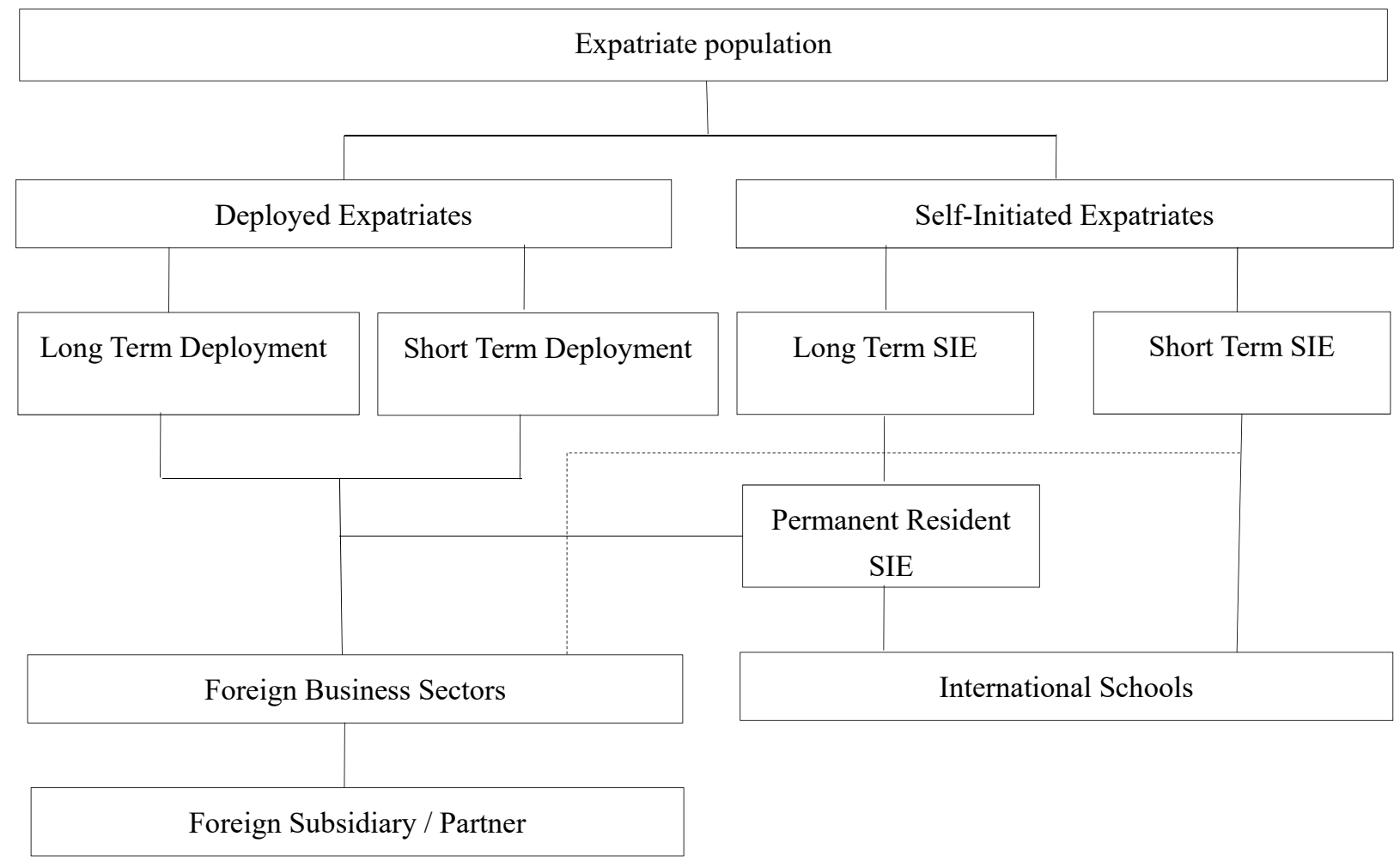

Figure 1. Differentiating Expatriate Types

As we can see in the above figure, there is an expatriate population which comprises of those who are deployed by a business concern and those who initiate their expatriation independently. There are, of course, other types of expatriates; there are tax exiles, the spouse or partners of primary expatriate, the students, the retirees, the romantics and those seeking 'greener pastures' etc. But for our purposes, we are looking at professional or career 
expatriates (also known as foreign assignees).

Whether the expatriate is deployed by the mother company, or they initiated their own expatriation, there will probably be a time-frame in mind. Some people are sent to cover short contracts of 12 or less months while others intend to work for longer periods.

International schools typically offer an initial 2 year contract. For this paper, we will take that as being the norm (Kataria \& Sethi, 2013). Also, bearing in mind that most international schools are single entity corporations that exist in a 'local' context, and they are not in the habit of sending or managing expatriates' off-shore or for that matter, even off-site. It could be argued that the management of their staff (expatriates) is very different to the examples that are presented in the bulk of the literature dealing with the management of expatriates.

The literature talks about the need for remote management, however international schools do not typically have experience, (nor the requirement) in fielding personnel all over the world to work on or engage in, different contracts of various duration. The staff they employ are, by definition, here at 'home'. Not the home of the staff member's, but the school's home base. Admittedly, there is some international travel at times, but again, it is not the company sending people, but the successful applicant flying him or herself and their family, (if applicable) to the country and city where the school is located. This is still far removed from the typical literature examples where the company is the agent sending staff all over the globe. Further, contrary to the bulk of expatriate management literature, the teacher is managed as a local. They pay taxes in the local currency, abide by local rules and regulations and, except from being citizens of another country, they are for all intents and purposes, local residents.

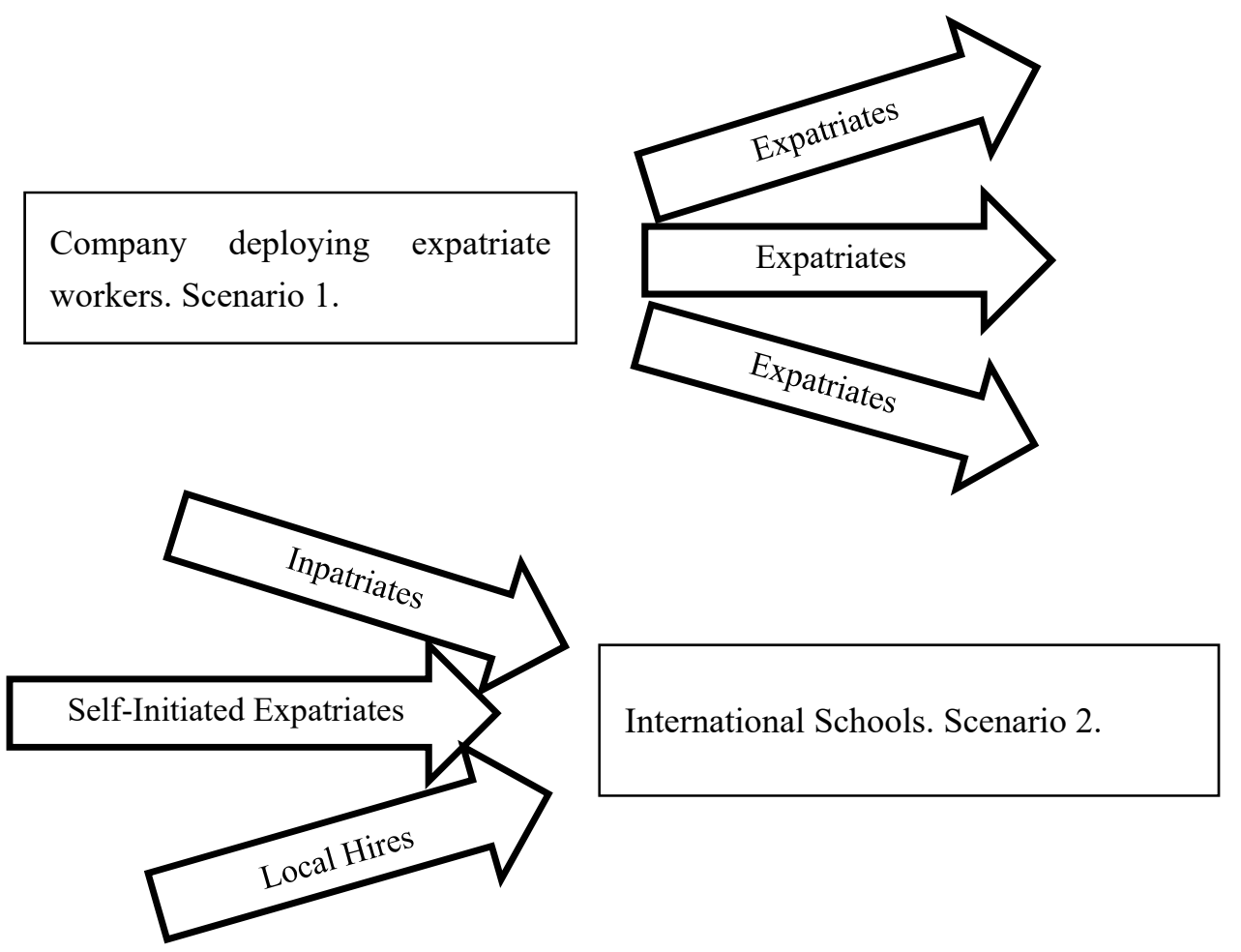

Figure 2. MNC vs International School Expatriate Model

The term Inpatriates is used to identify a subset of expatriates who are citizens of a foreign country working in the home country of their Multi-National Corporation MNC employer (Hill, 2007; Harvey \& Fung, 2000). These expatriates are sent to a foreign country by MNCs with the intent to control their operations and to provide technical and administrative services (Jun et al., 2001; Kataria \& Sethi, 2013). Apart from the notion of being 'sent' to a foreign country, the teachers in international school are brought from foreign countries.

As can be seen in the above figure, the typical, and oft referred to model of expatriation is diametrically opposed to the reality of internationals schools. The term 'Inpatriate' is used to describe SIE expatriates who are (at the time of recruitment) already domiciled in the foreign country and are hired as expatriates of foreign staff but done so on a local hire contract. This local hire contract is different to contracts offered to local indigenous staff. 
The HR focus in the first scenario is typical of the examples given in many text books. More companies are becoming international and as such, employing and deploying increasing numbers of expatriates to manage operations remote to the home-country or head office (Roberts et al., 1998). In this context, some of the challenges facing HR departments are:

- Deployment - Getting the right person with the right skill sets in the right location.

- The successful dissemination of knowledge and innovation - Ensuring that the company has access to best practice regardless of location.

- Identification and development of talent on a global basis - Identifying who has the requisite abilities and nurturing them.

This is turn has forced companies to develop HR policies, frameworks and procedures specifically targeted at international deployment of expatriates (Fadel \& Petti, 1997).

Some of the areas that the company's HR department needs to deal with include:

- Identification, assessment and selection of staff

- Determining actual total or 'all-in' costs for expatriate deployment and also determining whether to deploy or hire in-situ

- Creation of international job descriptions and KPIs

- Determining compensation and remuneration for a host of different locations that may or may not have totally different tax regimes and living expenses

- Assistance with relocation and (where required) storage of personal effects

- $\quad$ Support for the employee's family members who may either be accompanying the employee or remaining at 'home'.

It is immediately apparent that some of these roles and/or responsibilities are not applicable when looking at the HR department and HRM policies of an international school. International schools do not need to deploy expatriates. Nor do international schools need to ensure dissemination of knowledge in other locales; there are no other locales. International schools certainly look at skills sets and talent when recruiting staff members but the nurturing, if done at all, is limited to the staff member's contract at the school site.

There are however, some similarities between MNCs and international schools. They do both assess, select and recruit staff. However, they do not have anywhere near the same 'all in' costs for staff members. The contract at an international school is a local one that offers pretty much the same that would be on offer in the home country, for example, salary, medical insurance and housing assistance. Nor does the school need to develop different KPIs for different locations (Hocking, Brown, \& Harzig, 2007). The school only needs to develop KPIs and other job related documentation applicable for the host country laws and the school operational imperatives. Along the same lines, international schools do not have to figure and account for different tax regimes. The school only needs to meet tax legislation, as it is, in the host country and ensure compliance to any tax treatise between the teacher's country of citizenship and the host country.

The school does typically assist with relocation for the staff member and his or her family. Likewise, schools may, (to a greater or lesser degree) assist families with settling-in (Stahl \& Bjorkman, 2006), however most schools do not cover the end-of-contract relocation back to the staff member's home country.

The differences are significant and because of these, some of the HR practices that one reads about in various texts concerning expatriates and repatriation are not applicable in the context of an international school operating in one site in a foreign country. The following HR consideration are presented in this context, that is, of an international school operating as a local business in a host country (Shaffer, Harrison, Gregersen, Black, \& Ferzandi, 2006). An extensive literature review was undertaken focussing on Self-Initiated Expatriates, (SIE) and determined the following: "The literature presents a narrow focus on the most privileged of self-initiated expatriates and presents some important knowledge gaps." (Al Aris et al., 2013). Other researchers have echoed these same sentiments and observations.

Studies of international transferees have generally assumed that they are sent to a foreign country by their employer. In practice, many of these transferees make their own arrangements to get work. There are similarities with the more traditional expatriate forms and some important differences (Suutari \& Brewster, 2000).

As recently as 2013 Vaiman and Haslberger in their text dealing with talent management of self-initiated expatriates made the observation that their review of the literature found significant gaps in coverage. They cite 
the phenomenon of academics and teachers as SIE's. Interestingly, Vaimin and Haslberger's text is one of the few text directly related to the focus of this paper. While not a new phenomenon, a new and diverse breed of internationally mobile talent has caught the attention of researchers. These are the academics and teachers going abroad on their own initiative to teach and learn themselves; they are people on time off to explore the world, be it right after school or as a mid-career break; they are the professionals and experts independently seeking work in another country; and so on (Vaiman \& Haslberger, 2013).

This 'shortage' of, or 'gap' in the literature has been observed by many other researchers. In Howe-Walsh and Schyns' 2010 publication they state.

So far the literature has focused on the motivation to expatriate, on the one hand, or Human Resource Management (HRM) for international assignments within an organisation, on the other hand. Little regard is paid to the opportunities HRM can play in supporting the adjustment of self-initiated expatriates to the new organisation and culture.

So there is a definite gap in the knowledge, or at least in the publishing arena, about the impact HRM can have on the successful integration and development of SIEs. It is with this in mind that drove further reviews of the available literature. Closer examination found more confounding issues in that the literature still had an inherent bias of companies employing or wishing to employ global talent.

For organisations, it can be highly attractive to have international staff, especially as the competition between companies grows more and more internationally. Especially, in areas of skills shortages, the competition for talent is ever-increasing. Therefore, adopting an internationally focused HR strategy may enhance competitive advantage for the company. However, incorporating an international focus to HR practices at many organisations seems to be in its infancy. In order to attract and retain international staff and compete on the global talent market, HRM within organisations needs to become more purposeful and proactive (Howe-Walsh \& Schyns, 2010).

Schools are anomalies in that they operate very differently to a typical company. The competition for staff is based, for the most part, on three distinct attributes. The first is that they are Native English Speakers (NES), secondly, that they hold teaching qualification which in turn allow them to be licensed in the jurisdiction of the school and third, that they meet visa requirements and government imposed conditions such as eligibility to work, pay taxes and reside in the school's host country. So the attraction of diverse staff is less important than the attraction of NES, citizenship and age appropriate teachers. Once again, the inherent assumptions and biases in the literature fails to completely address the anomaly that is the international school.

Research into expatriates has mainly focused on employees sent on assignments by their company (Richardson \& Mallon, 2005; Suutari \& Brewster, 2000). However, self-initiated expatriation where an individual achieves employment outside their home country is an equally important topic (Howe-Walsh \& Schyns, 2010). There are however, many valid observations, suggestions and opinions that can in fact complement or be utilised by school HR departments. As mentioned earlier, a large amount of the prior literature on expatriates has focused on employees undertaking international assignments. These two groups of expatriates can be contrasted to each other. Employees on international assignments have a job arranged for them by their company before they leave their home organisation. In contrast to self-initiated expatriates, employees on international assignments usually receive training prior to leaving for assignment. In addition, a typical package for international assignees can include culture and language training as well a compensation package that takes into account educational benefits for children, rental supplements etc. (Peterson, Napier, \& Shim, 1996; PricewaterhouseCoopers, 2005).

SIE applicants to international schools are proactive by their very nature. They seek out schools to apply for based on several criteria. Obviously there is the need or desire to be employed, the desire to work in certain types of locales or the desire to work and live in a particular country. It is this last aspect, the desire to live and work in a particular country that probably has the most ramifications vis-à-vis opportunities for HR department to not only support SIE applicants in their workplace but to also assist with the transition to a new country for both the applicant and his or her family. There are some other differences between SIEs and Inpatriates or Newcomers that warrant investigation.

In the case of the country's culture, the inpatriate would probably have a deeper and more accurate understanding of the social mores and expectations. For both parties, the organisation culture is an unknown and this is an area that HRM can definitely support during on-boarding and ongoing coaching and performance management. The job characteristics are, in most instances, known by both parties. They have undergone teacher training and have pretty much the same theoretical knowledge of curriculum, pedagogy and classroom practices. With regards to teaching, the inpatriate may have taught at government schools but otherwise, both parties 
probably have very little accurate knowledge about the profession outside the internationals school setting. The final aspect, that of Job Characteristics will be an unknown to both parties and once again HR has an important role to play is disseminating information and developing the corporate culture.

Table 2. Differences between SIEs and Newcomers

\begin{tabular}{ccc}
\hline & Self-initiated Expatriates & Newcomers \\
\hline Country culture & Unknown & Known \\
Organisational culture & Unknown & Known \\
Job Characteristics - general & Known & Known \\
Job Characteristics - Country level & Unknown & Unknown \\
Job Characteristics - Organisation & Unknown
\end{tabular}

Source: (Howe-Walsh \& Schyns, 2010)

In terms of HRM and HR practices there are some significant differences in intervention or management of expatriates who have moved to take up the position and the local hires who applied domestically. For example, expatriates that have applied for a job and move abroad to take up that position will probably be more prepared for the job related aspects of their move, though maybe not for the intercultural challenges. On the other hand, expatriates who move to a certain country because of the country rather than the job may be more prepared for intercultural challenges than for the challenges involved in starting a new job abroad. In addition to the differences within the group of expatriates, the company involved may have more or less interest in a successful acculturation, depending on whether they particularly wanted the expatriate prior to expatriation and, consequently, spend more effort in helping the expatriate to adjust. Expatriates that live in the country before applying for a job, in contrast, may be considered more equally to other (host country / nationals) applicants (Howe-Walsh \& Schyns, 2010).

The argument for HR to consider and account for SIEs in its day-to-day management is compelling. There is “... recognition by academic scholars, business, and policy-makers that SIEs are valuable international human resources that benefit organizations and economies." (Dickmann \& Baruch, 2011). The UN Department of Economic and Social Affairs' Population Division (2011) estimates that in 2010 there were 214 million individuals who were undertaking an international mobility. The previous survey had been undertaken in 1990 and showed an increase of some 58,000,000 people (3\% of the world's population. "This same report explains that for the period of 2010-2050, the number of individuals moving from developing to more developed regions is expected to be 96 million. Among these individuals, self-initiated expatriates (SIEs) will continue to represent important international human resources for organizations for various reasons (Dickmann \& Baruch, 2011). There are also intrinsic benefits in hiring SIEs. If this is not their first overseas position they could very well bring a more developed sense of local and global markets, languages and cultures and coupled with this, cost less than the typical deployment of expatriates to a foreign office in that they are already in-situ.

The challenges facing schools in attracting and retaining teachers has been promulgated in many articles and journals. Once again however, these articles tend to be focused on state and/or government schools in western countries addressing what is widely termed, a teacher shortage. These articles have merit and provide insights and strategies for the principals and superintendent of states suffering a teacher shortage but they do not relate to international schools per se. In fact, if anything, international schools are one of the contributors to the teacher shortage. Teachers are not only leaving the profession in ever increasing numbers but a large and growing proportion are leaving government and state schools where they have no control over student body demographics and instead applying to teach overseas in international schools where it can be argued that there are not the same discipline problems or student ability problems. International school can and are very selective in which students they accept and this in turn makes a huge difference on the actual job of teaching.

The reality for international schools is that they advertise through an agency and/or through their own website and teachers apply to teach. The attraction and retention concerns are not as acute as they may be in state, public and/or government schools for teachers in general however there are still some areas that need refining and attention. International school invest a considerable amount of money, time and resources in and for teachers. The issue for international schools is the attraction and retention of millennial aged teachers.

Millennials are looking for four major qualities in socially responsible companies: They want companies to be actively invested in the betterment of society and the solution of social problems. They want companies that prioritize "making an impact" on the world around them. They want companies to be open and honest about their 
efforts - and to be public about their pro-social initiatives. Finally, millennials want companies to involve their customers in their good works. They want an opportunity to give back - whether it's with a gift of their time or of [sic] their money (Landrum, 2017).

This sentiment of wanting to give back as proposed by Landrum is one that has been turning up increasingly in much of the popular literature and beginning to emerge in some of the academic writings (Breeze, 2013). If this is indeed the case, any survey being contemplated should provide opportunities for Millennials and for that matter, all generational groups, to comment on whether or not this was or is a factor in their decision making.

Employees who leave prior to the completion of their contractual obligations, or those people who fail to deliver what key performance indicators are expected or agreed upon, can be an accurate barometer of the cultural climate of the organisation. Just as culture is the shared understandings of a society, workplace culture is the shared understandings and assumptions held within the workplace by all members of the workforce. These assumptions and understandings relate to the behaviours that are expected and accepted by the rest of the workforce.

These beliefs, over time, create and reinforce beliefs about what behaviours are accepted and expected in any given situation. These can be referred to as corporate stories. These stories, like any other story, are communicated through language. Corporations are no different in that they share stories through verbal and non-verbal language. When looking at the manifestation of these stories we see the corporate symbols and rituals. These combined form what is commonly called the corporate culture (Landrum, 2017). In the realm of international schools, heads of schools, principals and recruiters need to reflect and take the position of a prospective employee and ask themselves why they would want to work at this school as opposed to another school 'down the road' as it were. Hopefully this reflection will elicit further questions to think about. Is this school a place where people can feel valued? Is it a place where younger teachers can feel mentored and supported in the early years of their career? In an attempt to answer these questions (and more) the author undertook a survey of 191 teachers representing male and female Baby Boomers, Gen X'ers and Millennials with a view of determining the main attractors and the main reasons for choosing other schools.

\section{Materials and Methods, Area Descriptions, Techniques}

The following results are based on research carried out by the author as part of his dissertation. In a survey of 191 international school teachers in Bangkok the following was found. Twenty one percent of teachers applied from their home country, $66 \%$ were already teaching overseas and applied from their (at the time) current location and $12 \%$ applied as local hires. During interviews of 24 international school teachers it was determined that $100 \%$ of them were Self-Initiated Expatriates.

Table 3. Comparing Types of Expatriation

\begin{tabular}{ccc}
\hline & Self-Initiated Expatriates & International Assignees \\
\hline Initiation & Self & Company \\
Pre-departure preparation, training etc. & Self & Company \\
Time perspective & No Limit & Limited \\
Job secured prior to expatriation & Yes or No & Yes \\
Compensation package & No & Yes \\
Support in non-work issues & No & Yes \\
\hline
\end{tabular}

Source: (Howe-Walsh \& Schyns, 2010)

The above table does not reflect some of the SIE experiences in the field of international school teaching as determined through a survey of 191 international school teachers in Bangkok. The respondents were separated into SIE $(89.9 \%)$ and Inpatriates $(10.9 \%)$. All of the SIEs reported that they were advised of, and agreed to the compensation package prior to leaving their home country. Furthermore, $100 \%$ of SIEs surveyed, had their job placement secured prior to moving. Interestingly, only $67 \%$ of SIE respondents indicated that they received any assistance in non-work issues such as housing while only $6 \%$ indicated that they received any assistance whatsoever for spouse and family.

There were 6 underlying hypotheses that were to be tested. The first was that there is a relationship between job expectations and age. The second hypothesis was that there is relationship between the value placed on performance management and age. The third hypothesis was that there is a relationship between the importance placed on remunerations packages and age. The fourth hypothesis was that there is a relationship between 
workplace culture and age. The fifth hypothesis was that there is a relationship between job security and age and the final hypothesis was that there is a relationship between sense of fit and age. The driver behind these hypotheses was the belief that millennials have different views about many of the school offerings than there Gen $\mathrm{X}$ and Baby Boomer counterparts and that understanding these differences would provide school administrators and leaders with greater leverage in which to attract and retain these younger teachers.

In order to either reject or accept these hypotheses the author designed a survey which was piloted among a cohort of representational teachers and subject experts. Additionally, the author conducted a series of in-depth interviews with a group of teachers. The interviews were conducted off-site form the school.

The interviews were semi-structured, in that guiding questions were developed with allowances made for the respondent to add to the answers as she or he saw fit. It was also anticipated that the responses may cause or invite the interviewer to follow different threads or pathways in and around the topic discussed. The people chosen for interview were a valid demographic representation of the target population.

The focus group for the interviews were heads-of-schools and school principals. The aim of the interview was to gauge the type and scope of initiatives and interventions being utilised to attract, develop and retain teachers and whether there was any thought given to different generational groups of prospective teachers and if so, what measures were being taken to engage them in the attraction, development and retention cycle.

The Kruskal-Wallis Test is a non-parametric alternative to the one-factor ANOVA test for independent measures. It relies on the rank-ordering of data rather than calculations involving means and variances, and allows researchers to evaluate the differences between three or more independent samples (treatments). Due to the fact that there are three distinct generation groupings it was decided that this would be a suitable test to implement.

When comparing the rankings provide by the three generational groups using the Kruskal-Wallis non parametric test the following significant relationships were discovered.

Respondents were asked to rank 6 information channels from most important to least important in the context of what they would use when trying to find out information about schools. Comparing the three generations the following relationship can be seen.

As previously mentioned, there is no conclusive data available on the actual number of international school teachers in the Kingdom of Thailand. This is partly based on a refusal or inability by the Royal Thai Immigration Department to divulge number of people who hold NON B Visa under the category of teachers. Further compounding this is the fact that many schools purport to be international when in fact they may not qualify according to the criteria presented earlier in this paper.

The initial survey was piloted among 30 teachers. The group of teachers reflected the make-up of the planned target group in that there was an even distribution of Baby Boomers ( 5 male and 5 female), Gen X ( 5 male and 5 female) and Gen Y (5 male and 5 female) teachers. Feedback was sought vis-a-vis the

- clarity of questions

- the presence of any inherent bias and

- industry specificity with regards to terminology and phrases

These 30 teachers provided invaluable feedback which helped form the second pilot survey. The survey was piloted a second time with a group of 12 (Note 1) teachers to confirm whether or not the modified and updated questions were easily understood. The author was also checking if there was a commonality of meaning as well as to calculate the time-cost in completing the survey. There was a uniformity of answers when asking the respondents to describe the questions and their meanings, as well as the supposed intention behind each question. Subjecting the survey to Cronbach's Alpha test and realising an Alpha value of 0.8952 satisfied the need for internal consistency vis-à-vis the survey questions that had Likert type scales. It was also confirmed that the survey could be completed within $10-15$ minutes depending on the length and detail of short answer and paragraph answers.

The survey was then compiled into a Google Form ${ }^{\mathrm{TM}}$ which would enable it to be sent out electronically and returned anonymously, via online link, to the researcher. The options on Google Forms ${ }^{\mathrm{TM}}$ allowed the author to create settings where a respondent has to answer all questions and could only submit a form once. There were 191 responses. Table 12 overleaf illustrates the demographic breakdown (Note 2). The resultant survey had a total of 27 questions comprising multiple choice, short answer, paragraph answers and Likert (Note 3) type rankings. There were both quantitative and qualitative questions in the survey. Questions were analysed using the appropriate methodology best suited to the question format. The analysis and the tool used is explained prior to 
each set of findings.

The survey was distributed to 23 schools through the head of school or principal. Guarantees were made as to the anonymity of responses.

Table 4. Final Survey Population

\begin{tabular}{cccc}
\hline & Baby Boomers & Gen X & Gen Y Millennial \\
\hline Male & 30 & 32 & 31 \\
Female & 31 & 30 & 37 \\
\hline
\end{tabular}

\section{Results}

International school owners, school leaders and the associated key decision makers need to be aware of changing trends in their marketplace and to be looking at both tactical and strategic initiatives to deal with these changes. First and foremost is the changing demographics within the teaching profession itself. Baby Boomers are reaching retirement age and leaving the profession, Gen X'ers, for the most part, seem pretty stable, but they too are ageing and the number of Millennials entering the profession is less than was previously anticipated. In other words, the supply of suitable teachers is becoming tighter and competition to attract high-calibre teachers is going to increase.

Additionally, and compounding this reality even further in the coming years, is the fact that teaching studies are not as appealing to Millennials as they were to Baby Boomers and universities are struggling to attract top-shelf students. The Millennials who are entering teaching studies aren't, according to many pundits, top-shelf students. (HR Exchange, 2016).

Why is this so? It is, in part, because the profession is not seen as glamorous or exciting. "Third Way", a Washington, D.C-based public policy think tank, surveyed high-achieving undergraduate students and found that 50 percent of these students believe teaching has become less prestigious in the last few years. Most respondents consider education as one of the easiest majors and see it as a profession that average students choose. Consequently, one of the primary problems the field faces is determining how it can attract the over-achieving, motivated, and ambitious millennials (HR Exchange, 2016).

Remuneration, or the lack thereof, is another aspect that is turning away potential teachers. Admittedly, the living cost in Bangkok is less, however this too is rising. The reality for many international teachers is that they come to a school for $2-3$ years and may have financial obligation back in their home countries. Student loans and other burdens do not decrease just because the person changes location to one where living expenses are lower. Generally speaking, the teaching profession-and more specifically, its pay structures and retirement systems - have not changed much in more than 40 years. These systems no longer meet the needs of new graduates, and they appear to be driving high-achieving millennials into other professions that have more innovative practices. For example, nursing, law, and medicine have changed in how employees are trained, promoted and compensated (HR Exchange, 2016).

International schools have always preferred a minimum of two years of experience, which allows the teacher to prove their pedagogical knowledge, classroom management skills and lesson planning, delivery process and to become professionally confident before confronting the new cultural challenges faced when moving away from home. However, a significant percentage of schools, often local international schools with lower fees and therefore less money to pay overseas teachers, have begun to welcome flexible Newly Qualified Teachers (NQT) to supplement their staff (Jacoutot, 2018).

This phenomenon is not new to Thailand. There are unfortunately, many schools employing teachers with little or no teaching experience. Compounding the problem even more is that some of the local international schools are often unaware of the legitimacy (or otherwise) of the credentials being proffered and are unable or unwilling to take on serious reference checking or substantiation of claims made by teacher applicants.

In recent years, though, various ministries of education have either created new requirements or strengthened old ones, so that many countries now require two years of experience and/or have minimum age limits. Notably China, with more than 300 international schools, stopped almost all schools from hiring international teachers with less than two years of post-qualification experience in 2012, creating an increase in demand for more experienced teachers; other countries such as Thailand, Egypt and Indonesia appear to be following suit. (Jacoutot, 2018). 


\section{Discussion}

The survey and associated interviews determined that there are in fact different perceptions and values vis-à-vis workplace sense of fit, workplace sense of value and workplace aspirations based upon age and to a lesser degree, gender. There were incidences where the survey responses tallied with the literature concerning millennials and their aspirations for work life balance and work-place choices. There were also points of separation or disagreement with the literature in that some proponents would suggest that millennials are focussed to a large degree on giving back and being 'connected'. These issues did arise in the survey but to a significantly lesser degree than one could expect based upon literature and pre-existing surveys. This could be attributed to the geographic location of surveys that the various journals undertake, it would seem that the bulk of them are carried out in the USA among US millennials, whilst the population surveyed in Bangkok were a much more diverse group of people with citizens of Australia, the UK, Canada, the USA, New Zealand and South Africa included in the target population. Comparable studies in Europe are almost non-existent. The first official study into European Millennial behaviour was first published in 2006 by Forrester Consulting. This document, titled Is Europe ready for the Millennials? (Corvi, Bigi, \& Ng, 2015).

The survey carried out in Bangkok was focussing on addressing 6 distinct hypotheses. All of them were based on determining if age was a major impact on behaviour. The first hypothesis proposed that there is a relationship between job expectations and age. The Independent Variable (IV) was jobs expectations while the Dependent Variable (DV) was retention. This relationship was expected and was central to the proposal of this paper. It is felt that millennials are very different to their older Gen X and Baby Boomer cousins, especially in the way they view their jobs and their career expectations. Much of the literature talks about experiences versus careers. Schools can package the experience aspects of their school, for example, the location, the local cultural and geo physical attractions as well as the opportunity to use the school's location as a travel hub. Added to this, many millennials are not typically looking to stay beyond 2 or 3 years. Promoting career movement within the school is another way schools can differentiate themselves form the competition. In other words, show the young applicant ways in which he or she may be able to develop their career through a variety of 2 to 3 year positions. This could be, for example, home room teacher for 2 years and then group leader, subject specialist or cost centre manager for an additional 2 years depending on their interests and qualifications.

Hypothesis 2 was that there is a relationship between performance management and age. The IV was performance management and the DV was retention. The interviews made a clear case for aged-based differences in perception vis-à-vis the value, importance and relevance of professional development. Many articles focussing on millennial aged teachers are arguing that mentors are viewed more highly than the traditional performance management. The 'what's in it for me' question is one that needs to be, and can be promoted in schools. Schools have an opportunity to demonstrate the difference between performance management as an audit and disciplinary function and show how they can use a coaching model and support mind-set that value-adds to the employee's employability down the line.

Hypothesis 3 proposed that there is a relationship between the importance placed on remuneration packages and age. The survey clearly showed that Gen X'ers were most highly focussed on their remuneration. The literature talks about millennials wanting to work with companies that can demonstrate a social conscience more than those that are seen as damaging or exploiting people or the environment. Schools have an opportunity to pull at the 'heart strings' and use their website to show the corporate social responsibility initiatives being undertaken by the school as well as any community service initiatives that may differentiate the school from local competitiors. The IV was remuneration packages and the DV was attraction. There was a significant difference in the way the different generations viewed remuneration and the various aspects that go to make up a remuneration package. The older Baby Boomers saw components such as medical insurance far differently than did millennials. Millennials are more focussed on flexibility in their salary 'packaging'. An example can be seen with schools that offer return to base annual flights home for staff and schools that offer the money equivalent of the airfare and allow the teacher to decide how and when to use the 'bonus'. Think flexibility and be flexible is the key message for HR departments.

Hypothesis 4 assumed there is a relationship between workplace culture and age. Some schools are now employing 3 generational groups. Initiatives to establish a positive corporate culture will go a long way to attracting millennial aged teachers. Testimonials, especially video testimonials by 'like aged' teachers are seen as an important channel of communication for schools to talk about the school mission, vision, it people and the priorities the school places on its people. The IV was workplace culture and the DV was attraction. The survey and resultant interviews showed a significant difference on the importance placed on workplace culture by the various age groupings. Interestingly, both Baby Boomers and Millennials placed more significance on this aspect 
than the Gen x cohort.

Hypothesis 5 proposed that there is a relationship between job security and age. The IV was job security and the DV was retention. There was a significant difference in the importance placed on job security by the three different generational cohorts. Millennial teachers are not looking for long-term security. Don't try to sell this. Instead, schools should be showing how working with them will make their employees more employable once they have completed their contracts. Clearly outline benefits for re-signing contracts and relationships the school may have with others schools teaching the same curriculum or affiliations the school may have with groups of schools.

Hypothesis 6 proposed that there is a relationship between sense of fit and age. The IV was sense of fit and the DV was retention. There was a significant difference in perceptions of the importance of 'fit' among the three generational groups. Millennials see 'fit' as an important aspect of the work/life balance and will not stay in a location where they feel that they are not being valued, that the school is not promoting values they hold dear or the culture of the school is one of negativity and competition.

\section{Conclusion}

Schools owners and administrators need to understand that there are several fronts that need to be dealt with if they are to ensure their sustained competitiveness. First, they need to maintain their international student numbers in order to be, and equally as important, to be seen as an international school. Secondly, the school needs to employ high-calibre teachers who are equal to or better than the teachers available in the expatriate's home country. This will ensure that the curriculum delivery is equal to or better than the home-country and as a result, the school alumni should be successful when applying to their universities of choice upon graduation. Third, the school needs to maintain a $45-55 \%$ balance of international students whilst acknowledging that the expatriate packages are being eroded and there are increasing numbers of in-situ expatriates that do not necessarily enjoy comprehensive packages that include their children's education costs.

Central to this paper was the notion of ways for schools to attract high calibre teachers. Some schools are fortunate in the location or proximity to attractions. One could argue that Thailand has a certain appeal as a destination and will always have teachers applying to work in their schools; however, this is not the focus of this section. It is not so much about getting teachers to apply, rather, it is about attracting top-tier teachers in an extremely competitive environment.

There are several things schools can do to attract top-tier teachers, especially, younger millennial-aged teachers. These recommendations would have schools undertake the following:

1. Increase the time investment on developing the 'work with us' or 'employment' section of the school's website. This needs to be more interactive with opportunities for prospective teachers to get a 'feel' for the school.

2. Coupled with overhauling the web presence is creating a more meaningful user-visit-experience. Schools can incorporate testimonials in written form or even more effective, videos of existing and past teachers commenting on teaching, working and living at the school.

3. Promote the professional development that the school offers teachers.

4. Link the professional development offering with either career possibilities at the school or admit that many teachers only want to teach for a limited tenure but, that those teachers who are successful at the school tend to move on to their first or second choice school. In other words, 'working with us' (the school) will enable the teacher to grow and develop and become more competitive as a teacher.

5. Appeal to the millennials sense of social contribution. Promote the Corporate Social Responsibility (CSR) initiative that the school is engaged in.

6. Transparency vis-à-vis salaries and benefits. Whilst many schools are reluctant to post specific salaries on their websites schools could allude to cost of living equivalency. For example, suggesting that the salary would enable teachers to bank a considerable portion alludes to the salary being high compared to the local cost of living.

7. Salary. Is there a need to keep salaries confidential? It is suggested that school administrators actually look at the rationale behind non-disclosure of salary. Could the school publish their salary table? What are the cost benefits behind doing so?

Of additional concern is the student body. Maintaining student numbers is a concern for schools at any time. However, in the international school context, this is more convoluted. There is the need to maintain overall 
student numbers as well as the need to maintain diversity and international student numbers. Many international schools 'sell' the idea of their international-mindedness and student diversity in their marketing materials. This is an acknowledgement of the importance diversity plays on parents when deciding upon a school for their children. Parents of local students along with parents of international students expect to see this diversity when visiting the school and making decisions about which school to send their children. In an effort to understand this more fully, several heads of school and school administrators were interviewed one-on-one. All of them reported that getting local students was not the issue. The challenges facing the schools were typically finding ways to attract and enrol foreign students in order to address their diversity and international student needs. A potential solution to this is presented below.

Assuming that the curriculum, teachers and current student body are representative of typical international schools in the area and that the current student body has a majority of international foreign students then the following proposal could be implemented. The school offers English language based academic based scholarships to foreign student's families that are not on expatriate packages. The cost of this could be absorbed by slow incremental rises in school fees for fee paying students and also allows the school to enrol local Thai (in this case) students on a one-for-one basis along with the scholarship winner. The bulk of the research and resultant literature concerned with the attraction, retention and development of quality teachers has been driven by the significant problems of teacher shortages and falling student performance in countries like the USA and, to a lesser extent, the UK and Australia. These shortages and performance levels have stimulated a lot of research however; this research is focused through a 'local' lens whether it is at a provincial, state or national level.

There is much less literature on the international school environment and it is argued that some of the problems befalling state and national education are not applicable to this international environment.

What is desperately needed is more research in this growing market that covers the international school sector as well as the environment in which it exists. Researchers need to examine teacher demographics, teacher supply, teacher training, deployment and incentives. The more research done now will hopefully lessen or mitigate some of the future surprises.

It is hoped that this paper will provide international school leaders and key stakeholders with an insight into:

- Key job-search decision-making impactors of millennial aged teachers.

- Strategies to attract suitably qualified teachers to apply for teaching positions

- Strategies to develop new and existing teachers and improve performance.

- Strategies to retain desirable teachers beyond their initial contract periods.

- Strategies for schools to maintain student diversity in order to qualify as international schools.

\section{Acknowledgement}

The author gratefully acknowledges the Dean-School of Management, Dr. Ousanee Sawagvudcharee for her cooperation and support in preparing this case study.

\section{Conflict of Interest}

The author declares that there is no conflict of interests regarding the publication of this manuscript. In addition, the ethical issues, including plagiarism, informed consent, misconduct, data fabrication and/ or falsification, double publication and/or submission, and redundancy have been completely observed by the authors.

$\begin{array}{ll}\text { ABBREVIATIONS (in order of appearance } \\ \text { NGO } & \text { Non-Government Organisation } \\ \text { ISC } & \text { International School Consultancy } \\ \text { EMI } & \text { English as Medium of Instruction } \\ \text { EMS } & \text { English Medium School } \\ \text { ISA } & \text { International School's Association } \\ \text { ESC } & \text { English Speaking Countries } \\ \text { SIE } & \text { Self-Initiated Expatriates } \\ \text { DE } & \text { Deployed Expatriates } \\ \text { LEE } & \text { Locally Employed Expatriate }\end{array}$


OECD Organisation for Economic Co-operation and Development

MNC Multi-National Company

KPI Key Performance Indicators

NQT Newly Qualified Teacher

\section{References}

Andrews, J. (2012). The report. Thailand 2012 (p. 194). Oxford Business Group. Retrieved from https://books. google.co.th/books?id=LBCrxwRkTZ8C\&printsec $=$ frontcover\&redir_esc $=\mathrm{y} \# \mathrm{v}=$ onepage\&q\&f=false

Anthony, W. P., Kacmar, K. M., \& Perrewe, P. L. (2002). Human Resource Management: A Strategic Approach (4th Ed.) New York: South- Western.

Arnold, C. L., Choy, S. P., \& Bobbitt, S. A. (1993). Modeling teacher supply and demand, with commentary (NCES 93-461). Washington, DC: National Center for Education Statistics.

Ballou, D., \& Podgursky, M. (1998). Teacher recruitment and retention in public and private schools. Journal of Policy Analysis and Management, 17, 393-417. https://doi.org/10.1002/(SICI)1520-6688(199822)17:3<393:: AID-PAM2>3.0.CO;2-B

Baruch, Y., Budhwar, P. S., \& Khatri, N. (2007). Brain drain: Inclination to stay abroad after studies. Journal of World Business, 42, 99-112. https://doi.org/10.1016/j.jwb.2006.11.004

Bell-Villada, G., Sichel, N., Eidse, F., \& Orr, E. (2011). Writing out of limbo: international childhoods, global nomads and third culture kids. Cambridge Scholars. UK.

Black, J. S., Mendenhall, M., \& Oddou, G. (1991). Toward a comprehensive model of international adjustment: An integration of multiple theoretical perspectives. The Academy of Management Review, 16(2), 291-317. https://doi.org/10.2307/258863

Bunnel, T. (2014). The changing landscape of international schooling: Implications for theory and practice. New York, USA: Routledge. https://doi.org/10.4324/9781315817705

Clark, N. (2017). World education news and reviews: The booming international schools sector.

Fajen, A. (2001). Teacher turnover: A national perspective. Columbia, MO: University of Missouri, System Consortium for Educational Policy Analysis.

Felker, J. A. (2011). Professional development through self-directed expatriation: Intentions and outcomes for young, educated Eastern Europeans. International Journal of Training and Development, 15(1), 76-86. https://doi.org/10.1111/j.1468-2419.2010.00369.x

Hayden, M., \& Thompson, J. (2008). International schools, growth and influence. International Institute for Education Planning. Retrieved from http://unesdoc.unesco.org/images/0018/001803/180396e.pdf

Hayden, M., \& Thompson, J. (2013). International schools: Antecedents, current issues and metaphors for the future. In R. Pearce (Ed.), International Education and Schools: Moving beyond the first 40 years (pp. 3-24). London: Bloomsbury. https://doi.org/10.4324/9780203761304

Hill, I. (2001). Early stirrings: The beginnings of the international education movement. International Schools Journal. European council of international schools. Retrieved from https://books.google.co.th/books?id= VpazmE97j7oC\&pg=PA16\&lpg=PA16\&dq=market + driven + international + schools\&source $=$ bl\&ots $=80-$

Hocking, J. B., Brown, M., \& Harzing, A.-W. (2007). Balancing global and local strategic contexts: Expatriate knowledge transfer, applications, and learning with a transnational organization. Human Resource Management, 46(4), 513-533. https://doi.org/10.1002/hrm.20180

Howe, N., \& Strauss, W. (2000). Millennials Rising: The Next Great Generation. New York: Vintage Books.

Jacoutot, D. (2018). Recruitment: The cream of the crop. BIS Magazine. Retrieved from http://www.bismagazine.co.uk/strategic/recruitment_articles/challenges.html

Kataria, N., \& Sethi, S. (2013). Making successful expatriates in multinational corporations. Asian Journal of Business and Economics, 3(3-4). Retrieved from http://www.onlineresearchjournals.com/ajbe/art/90.pdf

Keeling, A. (2015). All the world's a stage: Funding for independent schools. ISC Research. Retrieved from https://www.iscresearch.com/uploaded/images/Publicity/Funding_for_Independent_Schools_Feb_2015.pdf

MacKenzie, D. (2010). A World Beyond Borders: An Introduction to the History of International Organizations. 
Toronto: University of Toronto Press.

Maurette, M.-T. (1948). Techniques d'education pour la paix: existensils? (Response a une enquete de l'UNESCO) Monograph. International School of Geneva.

McNulty, Y., \& Brewster, C. (2016). The concept of business expatriates. Research Handbook of Expatriates. Retrieved from https://www.researchgate.net/publication/305592950_The_concept_of_business_expatriates

Reiche, S., \& Harzig, A. (2009). International assignments. International Human Resource Management, London: Sage Publications. Retrieved from http://harzing.com/download/ihrmchapter.pdf

Stahl, G. K., \& Bjorkman, I. (Eds.). (2006). Handbook of research in international human resource management. Cheltenham, UK: Edward Elgar. https://doi.org/10.4337/9781845428235

Suuthari, V., \& Brewster, C. (2000). Making their own way: International experience through self-initiated foreign assignments. $J$. of World Business, 35(4), 417-436. https://doi.org/10.1016/S1090-9516(00)00046-8

Tung, R., \& Lazarova, M. (2006). Brain drain versus brain gain: An exploratory study of ex-host country nationals in central and east Europe. The International Journal of Human Resource Management, 17, 1853-1872. https://doi.org/10.1080/09585190600999992

Vaiman, V., \& Haslberger, A. (2013). Talent management of self-initiated expatriates (1st ed.). Palgrave Macmillan. UK. Retrieved from https://books.google.co.th/books?hl=en\&lr=\&id=aAu8Guq24i4C\&oi=fnd $\& p g=P P 1 \& d q=$ self + initiated + expatriates + talent + management\&ots $=h \_V Z M o 0 i 5 h \&$ sig $=x O I 27 \mathrm{PppnxEOFz}$ WC5srNo6t4Dzk\&redir_esc $=\mathrm{y} \# \mathrm{v}=$ onepage $\& \mathrm{q}=$ self $\% 20$ initiated $\% 20$ expatriates $\% 20$ talent $\% 20$ management $\& \mathrm{f}=$ false

\section{Notes}

Note 1. The 12 teachers (4 from each of Baby Boomers, Gen X and Gen Y) were members of the original 30 teachers from the first pilot test.

Note 2. Some people prefer to see information in numerical form whilst other prefer a pictorial representation. The author is aware and empathetic and has therefore chosen to include both formats wherever possible.

Note 3. It is the most widely used approach to scaling responses in survey research, such that the term (or more accurately the Likert-typescale) is often used interchangeably with rating scale, although there are other types of rating scales. The scale is named after its inventor, psychologist Rensis Likert.

\section{Copyrights}

Copyright for this article is retained by the author(s), with first publication rights granted to the journal.

This is an open-access article distributed under the terms and conditions of the Creative Commons Attribution license (http://creativecommons.org/licenses/by/4.0/). 